\title{
Unusual Eye Trauma Caused by Hula Hoop: A Case Report
}

\author{
Naser Salihu',2, Qëndresë Daka ${ }^{1,2 *}$, Belinda Pustina1 \\ ${ }^{1}$ Department of Ophthalmology, University Clinical Centre of Kosova, Prishtine, Kosovo \\ ${ }^{2}$ Medical Faculty, University of Prishtina "Hasan Prishtina", Prishtina, Kosovo \\ Email: nasersalihu@yahoo.com, *qendrese.daka@uni-pr.edu, belindapustina@gmail.com
}

How to cite this paper: Salihu, N., Daka, Q. and Pustina, B. (2017) Unusual Eye Trauma Caused by Hula Hoop: A Case Report. Open Journal of Ophthalmology, 7, 191195.

https://doi.org/10.4236/ojoph.2017.73026

Received: May 2, 2017

Accepted: August 1, 2017

Published: August 4, 2017

Copyright (c) 2017 by authors and Scientific Research Publishing Inc. This work is licensed under the Creative Commons Attribution International License (CC BY 4.0).

http://creativecommons.org/licenses/by/4.0/

Open Access

\begin{abstract}
Introduction: Eye injuries are common in sports and have the potential for major morbidity with sight threatening consequences. However, a small number of sports, such as soccer, rugby or hockey are responsible for most injuries. To our knowledge, hula hoop penetrating eye injury is not described in literature. In this report, we present a case of an unusual eye injury caused by a hula hoop. Case presentation: A 17-year-old female was admitted as an urgent penetrating right eye injury caused by a hula hoop. Penetrating wound covered $2 / 3$ of the cornea and was associated with iris prolapses and incarceration; iridodialysis of more than half of the circumference, and traumatic cataract. Her best corrected visual acuity of the right eye was "hand motion". The second corneal wound in parallel with the first one was noticed while she was being treated surgically under general anesthesia. Iris was repositioned, anterior chamber was formed with the viscoelastic and wounds were repaired using 10-0 nylon sutures. Iridopexy was performed using straight needle 10-0 prolene, while standard cataract surgery with phacoemulsification and IOL implantation were done. The postoperative recovery was uneventful beside elevated intraocular pressure (TOD $=24 \mathrm{mmHg}$ ) that was treated successfully by topical beta blockers. Six months later, her best corrected visual acuity was 0.6 stenopeic, with evident linear corneal opacification and traumatic mydriasis. Conclusions: Although seemingly impossible, hula hooping can be dangerous to the eyes if practiced in incommodious areas and close to other people.
\end{abstract}

\section{Keywords}

Unusual Eye Trauma, Hula Hoop, Treatment

\section{Background}

The incidence of eye injuries due to sports has shown an increasing trend, ac- 
counting for up to $40 \%$ of all eye injuries requiring hospital admission [1] [2] [3]. These injuries have the potential for major morbidity with sight threatening consequences, however, about $90 \%$ of all these injuries could be prevented with proper education of athletes [4] [5]. The mechanisms of sport-related eye injuries most commonly involve blunt trauma, followed by penetrating or radiation injuries, whereas sports that are most commonly associated to eye injuries include team sports such as soccer, basketball, rugby, baseball, or hockey [4] [5].

Hula-hooping is a popular sport, particularly among school children, around the globe. This sport requires complex skills by which a hoop with its circular shape, is kept in steady oscillation parallel to the ground or other planes by means of coordinate oscillations of different parts of the body [6]. This sport is mostly performed without any protective measures and there are only a few hula-hooping-related injuries reported in the literature, mainly due to irresponsible use of the hula-hoop or the existence of previous diseases [6]. A search of the literature produced no evidence of any eye injury caused by hula-hooping. To our knowledge, here we report a case of an unusual penetrating eye injury caused by a hula-hoop that has not been previously described.

\section{Case Presentation}

A 17-year-old female was admitted to our clinic as an urgent case due to penetrating right eye injury caused by a hula hoop. The patient's sister lost control while hula hooping in the dining room, and after the hula hoop hit the wall it broke down causing a penetrating eye injury to the admitted patient. On examination, best corrected visual acuity of patient's right eye was "hand motion". A slit lamp examination revealed: a penetrating wound covering $2 / 3$ of the cornea between 11 o'clock and 4 o'clock associated with iris prolaps and incarceration; iridodialysis on more than a half of the circumference between 10 o'clock and 5 o'clock; and a traumatic cataract that made impossible the examination of the posterior segment (Figure 1).

She was given $1 \mathrm{~g}$ of cefazolin intravenously and a tetanus shot, given the concern of an open globe injury. She was brought to the operation theatre immediately where the surgical repair under general anesthesia was performed. After we repositioned the iris, we noticed the second corneal wound in parallel with the first one between 9 o'clock and 5 o'clock. Wounds were repaired using single 10-0 nylon sutures, whereas for iridopexy repairment, straight $10-0$ pro-



Figure 1. Penetrating corneal vound with iris prolaps and iridodislysis. 


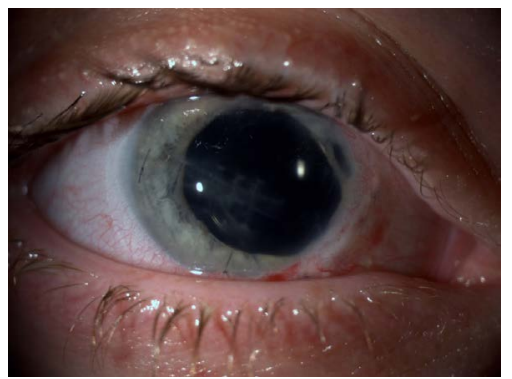

Figure 2. Patient one month after surgery.

lene needle was used. Standard cataract surgery and IOL implantation was also performed. The postoperative recovery was uneventful beside elevated intraocular pressure (TOD $=24 \mathrm{mmHg}$ ) that was treated successfully by topical beta blockers (Timolol). Dilated funds examination revealed no retinal whitening, tear or detachment. Six months later, her best corrected visual acuity was 0.6 stenopeic, with evident linear corneal opacification and traumatic mydriasis (Figure 2).

\section{Discussion and Conclusions}

The number of people participating in sports activities has been increasing over recent years due to better availability and improved socioeconomic status [7] [8]. With such activities, sport-related eye injuries have become a concern around the world as the incidence has been steadily increasing [2] [8]. These injuries can be fatal for sight, being responsible for up to one-third of all cases of blindness in the United States [9]. However, studies on the epidemiology, risk factors, mechanism of injuries and treatment of sport-related eye injuries are lacking, particularly for some recreative sports such as hula-hooping. We could not identify, through literature search, any single study that reported hoopingrelated eye injuries. Hula-hooping has to be performed in a spacious area as it is based on natural laws and principles of nature, therefore, its risk under safe condition is very little or absent [6]. Hooping related injuries, described in literature, include: myositis, bruises, oedemas, allergies, dermatitis, dizziness and headaches [10] [11] [12]. Penetration injuries by hula hooping have not been previously recognized.

In the present case, we describe the case of a young girl who sustained penetrating eye injury by a close distance brooked hula hoop ring that required surgical intervention. Owing to the hooping in dining room and the small distance between the two individuals, the broken hula hoop stroked the eye with a great velocity cumulating in a severe penetrating eye injury. This mechanism of injury highlights the importance of players to be aware of the risk of hula hooping in incommodious areas and close to other people. We reported immediate consequences of the eye injury that included penetrating corneal wound; iris prolaps and incarceration; iridodialysis and traumatic cataract. The management of the eye injury involved conservative therapy for infection prophylaxis and surgical intervention for the repairment of the wounds and 
cataract removal. However, six months later, our patient had a BCVA of 6.0 stenopeic, evident linear corneal opacifications, traumatic mydriasis and elevated intraocular pressure. Although seemingly impossible, this case impressively demonstrates the mis-belief that hula hooping is harmless and relatively safe, especially if practiced in inadequate places and close to other pople.

\section{Acknowledgements}

Not applicable.

\section{Competing Interests}

The authors declare that they have no competing interests.

\section{Funding}

We declare that we did not receive any funding for this work.

\section{Ethics approval and Consent to Participate}

Not applicable.

\section{Consent for Publication}

Written informed consent was obtained from the patient for publication of this case report and any accompanying images. A copy of the written consent is available for review by the Editor-in-Chief of this journal.

\section{Availability of Data and Material}

The data presented in this manuscript are fully anonymous.

\section{Authors' Contributions}

NS diagnosed the patient and performed the surgery. BP and QD performed the ophthalmological follow-up. QD wrote the manuscript together with NS. All authors read and approved the final manuscript.

\section{References}

[1] Jenkins, E., Hawkes, R. and Murray, A. (2016) A Scoping Review of the Associations of Golf with Eye Injuries in Adults and Children. Journal of Sports Medicine, 2016, Article ID: 7216325. https://doi.org/10.1155/2016/7216325

[2] Barr, A., Baines, P.S., Desai, P. and MacEwen, C.J. (2000) Ocular Sports Injuries: The Current Picture. British Journal of Sports Medicine, 34, 456-458. https://doi.org/10.1136/bjsm.34.6.456

[3] MacEwen, C.J. and McLatchie, G.R. (2010) Eye Injuries in Sport. Scottish Medical Journal, 55, 22-24. https://doi.org/10.1258/rsmsmj.55.2.22

[4] Rodriguez, J.O., Lavina, A.M. and Agarwal, A. (2003) Prevention and Treatment of Common Eye Injuries in Sports. American Family Physician, 67, 1481-1488.

[5] Drolsum, L. (1999) Eye Injuries in Sports. Scandinavian Journal of Medicine and 
Science in Sports, 9, 53-56. https://doi.org/10.1111/j.1600-0838.1999.tb00207.x

[6] Garcia-Falgueras, A. (2016) Hula Hoop in Fitness and the Centripetal Force. Psychology, 7, 1503-1517. https://doi.org/10.4236/psych.2016.713147

[7] Choi, J.S. and Shin, K.H. ()2008 Epidemiology of Leisure Sports-Related Ocular Trauma. Journal of Korean Ophthalmological Society, 49, 1658-1664. https://doi.org/10.3341/jkos.2008.49.10.1658

[8] Moon, S., Ryoo, H.W., Ahn, J.Y., Park, J.B., Seo, K.S., Shin, S.D., Song, K.J., Lee, K.H., Yoo, I.S., Cho, J.S., Ryu, H.H., Jeong, T.O., Yeom, S.R., Kim, Y.T. and Hong, S.O. (2016) Analysis on Sports and Recreation Activity-Related Eye Injuries Presenting to the Emergency Department. International Journal of Ophthalmology, 9, 1499-1505.

[9] U.S. Consumer Product Safety Commission (2000) Sports and Recreational Eye Injuries. U.S. Consumer Product Safety Commission, Washington DC.

[10] Yang, J.C. and Chang, K.C. (2003) Exercise-Induced Acute Spinal Subdural Hematoma: A Case Report. Kaohsiung JMed Sci., 19, 624-627. https://doi.org/10.1016/S1607-551X(09)70516-9

[11] Zaidi, Z.H. (1959) Hula-Hoop Syndrome. Canadian Medical Association Journal, 80, 715-716.

[12] Park, S.K., Kim, H., Lhee, H.Y. and Lee, K.B. (2007) Development of a Perirenal Hematoma after Hula-Hooping. Yonsei Medical Journal, 48, 868-870.

https://doi.org/10.3349/ymj.2007.48.5.868

\section{Submit or recommend next manuscript to SCIRP and we will provide best} service for you:

Accepting pre-submission inquiries through Email, Facebook, LinkedIn, Twitter, etc. A wide selection of journals (inclusive of 9 subjects, more than 200 journals)

Providing 24-hour high-quality service

User-friendly online submission system

Fair and swift peer-review system

Efficient typesetting and proofreading procedure

Display of the result of downloads and visits, as well as the number of cited articles

Maximum dissemination of your research work

Submit your manuscript at: http://papersubmission.scirp.org/

Or contact ojoph@scirp.org 